\title{
Exaggerated Phosphaturic Response to Circulating Parathyroid Hormone in Patients with
}

\section{Familial X-Linked Hypophosphatemic Rickets}

\author{
Elizabeth Short, R. Curtis Morrus, Jr., Anthony Sebastian and \\ Martin Spencer
}

From the Departments of Medicine and Pediatrics, University of California, San Francisco, California 94143

\begin{abstract}
A B S T R A C T To determine whether the phosphaturic response to circulating parathyroid hormone $(\mathrm{PTH})$ is exaggerated in patients with familial $\mathrm{x}$-linked hypophosphatemic vitamin D-resistant rickets (FHR), we examined the phosphaturic response to parathyroid extract (PTE) (administered intravenously in the posthypercalcemic state) in two unrelated adult hemizygotes with FHR. In these two patients whose plasma concentration of PTH was normal (determined by radioimmunoassay), neither vitamin $\mathrm{D}$ nor phosphate therapy had been given during the past $10 \mathrm{yr}$. Two normal men and a hypophosphatemic man with intestinal malabsorption, hypocalcemia, and osteomalacia served as control subjects. In all subjects, calcium gluconate was administered intravenously from 6 p.m. to 12 midnight at a rate that maintained the concentration of serum calcium at $13-15 \mathrm{mg} /$ $100 \mathrm{ml}$ during the administration of calcium. When normocalcemia had recurred the next morning, and the plasma PTH concentration and urinary excretion of cyclic $3^{\prime}, 5^{\prime}$-AMP were reduced, PTE was administered intravenously at successively increasing rates of $0.1,0.4$, and $0.8 \mathrm{U} / \mathrm{kg}$ per $\mathrm{h}$, each rate lasting $90 \mathrm{~min}$. Minutes after the initiation of PTE in the affected hemizygotes, fractional excretion of filtered phosphate increased from negligible values to values strikingly greater than those of similarly studied control subjects and plateaued at strikingly greater values throughout further administration of PTE. This phenomenon of exaggerated phosphaturia could not be attributed to volume expansion, decreases in serum concentration of calcium during the study, differences in percent of administered calcium
\end{abstract}

Dr. Short's current address is the Department of Medicine, Stanford University, Palo Alto, Calif. 94305.

Received for publication 16 October 1974 and in revised form 3 March 1976. retained, or hemodynamic changes. Only the phosphaturic response to PTE appeared to be exaggerated. At any cumulative dose of PTE, urinary excretion of cyclic $3^{\prime}, 5^{\prime}$-AMP in the hemizygotes was indistinguishable from that of control subjects. The findings in this study suggest that in patients with FHR, circulating $\mathrm{PTH}$ is required for the genetically transmitted abnormality to be physiologically expressed as a reduction in net renal reabsorption of phosphate, and that this physiological expression of the genetic abnormality is expressed fully at normal or nearly normal circulating levels of PTH.

\section{INTRODUCTION}

Familial $x$-linked hypophosphatemic rickets $(F H R)^{1}$ is an $\mathrm{x}$-linked dominant genetic disease characterized by lifelong hypophosphatemia, increased renal clearance of phosphate, normocalcemia, and, in children, rickets resistant to treatment with vitamin D in amounts predictably curative of rickets caused by simple deficiency of vitamin $\mathrm{D}(1,2)$. In patients with $\mathrm{FHR}$, reduced renal tubular reabsorption of inorganic phosphate (TRP) is not necessarily associated with a demonstrable increase in the concentration of circulating parathyroid hormone (PTH) (3-6). Glorieux and Scriver proposed that in FHR the parathyroid-hormone-responsive component of renal phosphate transport is genetically altered in a way that renders it physiologically unresponsive to circulating PTH (7). This proposal is based on their observations that in affected hemizygotes, the

\footnotetext{
${ }^{1}$ Abbreviations used in this paper: cAMP, 3',5'-cyclic AMP; $\mathrm{FE} \mathrm{PO}_{4}$, fractional excretion of filtered phosphate; FHR, familial $x$-linked hypophosphatemic vitamin D-resistant rickets; GF, glomerular filtrate; iPTH, immunoreactive parathyroid hormone; $\mathrm{PAH}$, paraaminohippurate; PTE, parathyroid extract; $\mathrm{PTH}$, parathyroid hormone; TRP, tubular reabsorption of inorganic phosphate.
} 
measured magnitude of reduction in renal phosphate reabsorption remained unchanged over a 10 -fold increase in plasma concentration of endogenous PTH (3), despite intravenous administration of a large amount of PTH (7). They confirmed previous observations that experimental hypercalcemia is attended by an increase in the value of TRP (8-11), and interpreted this as evidence that induced hypercalcemia per se increased renal phosphate reabsorption via a transport system independent of that normally responsive to PTH. Yet, an increased renal responsiveness to the phosphaturic effect of normal (3) (or even reduced, [4]) concentrations of circulating $\mathrm{PTH}$ could explain the characteristic reduction of TRP in patients with FHR (12) as well as the increase in TRP that attends sustained experimental hypercalcemia in these patients (8-11). Furthermore, if hemizygotes were hyperresponsive to the phosphaturic effect of normal concentrations of $\mathrm{PTH}$, induction of greater concentrations of circulating PTH might not induce a greater magnitude of phosphaturia. In the pres- ent study of two adult hemizygotes with FHR, neither of whom had been treated with phosphate or with vita$\min \mathrm{D}$ for at least $10 \mathrm{yr}$ before the study, we have investigated the phosphaturic response to graded increments of experimentally administered parathyroid extract (PTE; para-thor-mone, Eli Lilly and Co., Indianapolis, Ind.) after hypercalcemia of a degree and duration sufficient to induce values of TRP approaching $100 \%$, and, presumably, to sustain suppression of PTH secretion. Previous studies suggest that experimentally administered PTE can elicit a phosphaturic response in some patients with FHR after sustained hypercalcemia $(13,14)$.

\section{METHODS}

Study subjects. Two unrelated, previously unreported, adult male patients with $\mathrm{x}$-linked hypophosphatemic rickets were studied (Table I, Fig. 1). Both patients had severe rickets in childhood and persisting hypophosphatemia, but neither had been treated with vitamin $D$ within the last $10 \mathrm{yr}$. Untreated hemizygotes were studied to best examine

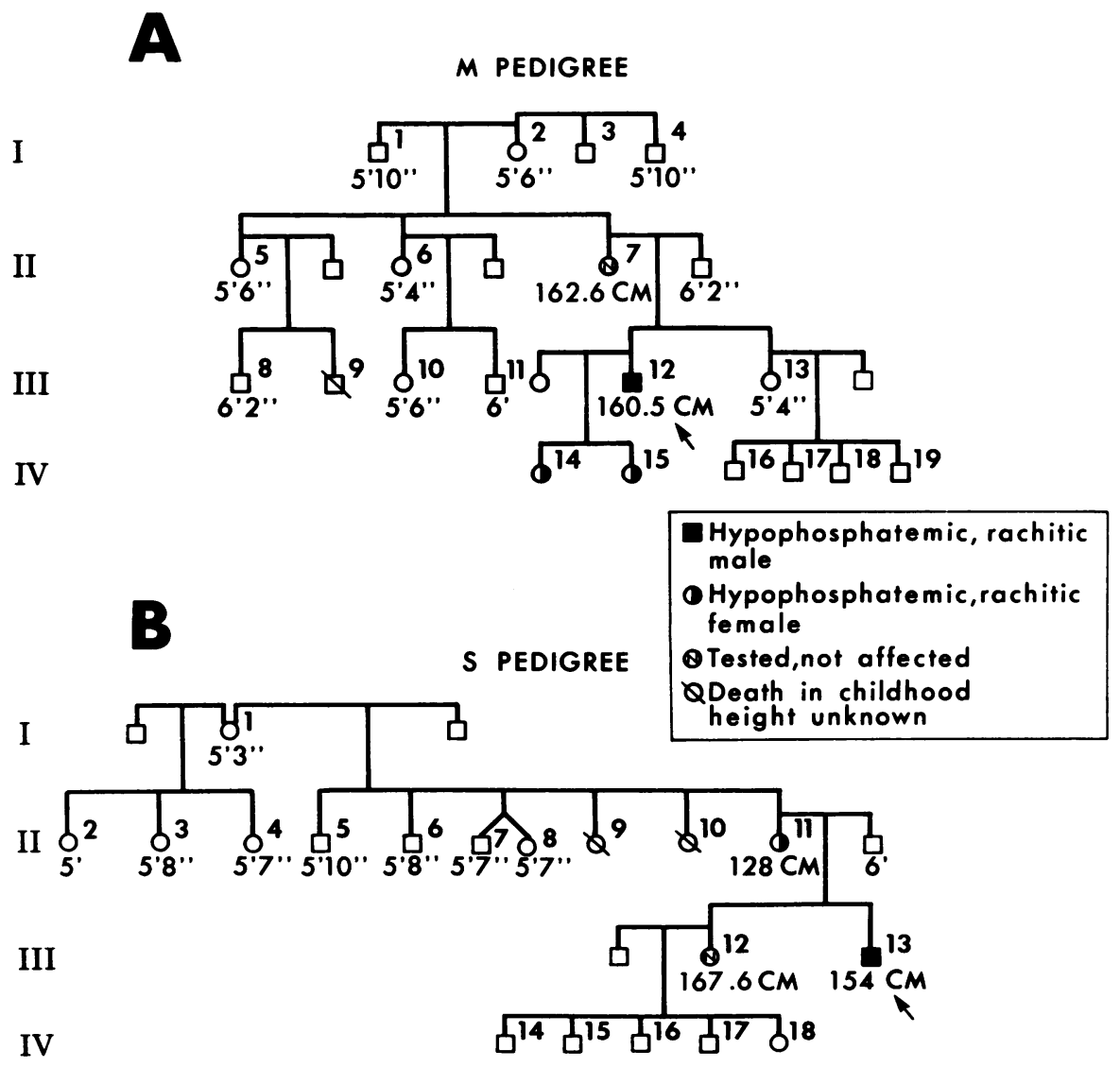

FIgURE 1 Pedigrees of two unrelated families with FHR. Heights of adult members that are designated in feet and inches are by history; most members of generations I and II are dead. Heights recorded in centimeters $(\mathrm{cm})$ are measured. All children (IV) in both pedigrees are within current age-adjusted heights except two affected females ( $M$ IV-14, $M$ IV-15) who have been treated since infancy. 
TABLE I

Biochemical, Physiological, and Clinical Data on Members of Two Pedigrees with FHR

\begin{tabular}{|c|c|c|c|c|c|c|c|}
\hline \multirow[b]{2}{*}{ Subject } & \multicolumn{4}{|c|}{ M pedigree } & \multicolumn{3}{|c|}{$S$ pedigree } \\
\hline & $\begin{array}{c}\text { G. M. } \\
\text { (III-12) } \\
\text { Proband }\end{array}$ & $\underset{\text { (II-7) }}{\text { H. M. }}$ & $\begin{array}{l}\text { L. M. } \\
\text { (IV-14) }\end{array}$ & $\begin{array}{l}\text { S. M. } \\
\text { (IV-15) }\end{array}$ & $\begin{array}{c}\text { J. S. } \\
\text { (III-13) } \\
\text { Proband }\end{array}$ & $\begin{array}{l}\text { M. S. } \\
\text { (II-11) }\end{array}$ & $\underset{\text { (III-12 }}{\text { J. S. M }}$ \\
\hline Sex & $\mathbf{M}$ & $\mathbf{F}$ & $\mathbf{F}$ & $\mathbf{F}$ & $\mathbf{M}$ & $\mathbf{F}$ & $\mathbf{F}$ \\
\hline Age, yr & 42 & 65 & $10.3 \frac{1}{2}$ & $72 / 12$ & 43 & 73 & 45 \\
\hline Height, $\mathrm{cm}$ & 160.5 & 162.6 & $130.5\left(-2 \frac{1}{2} \mathrm{SD}\right)$ & $113\left(-2 \frac{1}{2} \mathrm{SD}\right)$ & 154 & 128 & 169 \\
\hline Weight, $\mathrm{kg}$ & 88 & 73 & $28.9(-1 \mathrm{SD})$ & $19.5(-2 \mathrm{SD})$ & 58 & 53.7 & 91 \\
\hline \multicolumn{8}{|l|}{ Serum } \\
\hline $\mathrm{Pi}, \mathrm{mg} / 100 \mathrm{ml}$ & $1.7-2.0$ & $2.7-3.7$ & $2.3 *$ & 2.4* & $1.4-1.8$ & $1.4-1.5$ & $2.7-2.8$ \\
\hline $\mathrm{Ca}, \mathrm{mg} / 100 \mathrm{ml}$ & 9.3 & 9.6 & 10.2 & 10.0 & 9.8 & 8.4 & 8.9 \\
\hline $\mathrm{Mg}^{++}, \mathrm{mg} / 100 \mathrm{ml}$ & 2.0 & 2.0 & 2.1 & 1.9 & 1.8 & 1.7 & 1.8 \\
\hline $\mathrm{Na}^{+}$, meq/liter & 140 & 145 & 139 & 138 & 138 & 138 & 140 \\
\hline $\mathrm{K}^{+}$, meq/liter & 4.0 & 4.0 & 5.0 & 4.2 & 4.2 & 4.7 & 4.6 \\
\hline $\mathrm{Cl}^{-}$, meq/liter & 103 & 104 & 104 & 103 & 96 & 104 & 108 \\
\hline $\mathrm{HCO}_{2}$, meq/liter & 25 & 26 & 25 & 25 & 24 & 26 & 25 \\
\hline Alkaline phosphatase, $I U$ & 125 & 70 & 309 & 342 & 190 & 143 & 45 \\
\hline Total protein, $\mathrm{g} / 100 \mathrm{ml}$ & 7.0 & 6.9 & 7.4 & - & 7.4 & 5.9 & 6.9 \\
\hline Albumin & 4.1 & - & 4.8 & - & 4.4 & 3.3 & 4.3 \\
\hline Globulin & 2.9 & - & 2.6 & - & 3.0 & 2.6 & 2.6 \\
\hline Plasma iPTH, $p g / m l$ & 347 & 420 & - & - & 260 & 370 & - \\
\hline$C_{\text {Creat, } \operatorname{ml} / \min }$ & 98 & 88 & - & - & 90 & 60 & 143 \\
\hline TRP, (\%) & $46-68$ & $85-91$ & 77 & - & $66-81$ & $62-72$ & 85 \\
\hline \multicolumn{8}{|l|}{ Therapy } \\
\hline Vitamin $D_{2}, U / d a y$ & None & None & 25,000 & 15,000 & None & None & None \\
\hline Phosphate, $m g P_{i} / d a y$ & None & None & 400 & 200 & None & None & None \\
\hline Radiological & & & & & Classic & & \\
\hline Skeletal & & & & & Osteomalacia & Classic $\ddagger$ & \\
\hline Abnormalities & Classic & None & Active rickets & Active rickets & Pseudof ractures & Osteomalacia & None \\
\hline Osteotomies & Age 13 & None & None & None & Age 5 & Age 20 & None \\
\hline
\end{tabular}

Abbreviation: CCreat, renal clearance of creatinine.

* Measurement was made during a period in which patient's therapy included inorganic phosphate.

$\ddagger$ Bowed legs, shortened, coarsely trabeculated long bones, and bony overgrowth at muscle attachments.

the single gene effect. Neither patients nor affected members of their pedigrees (Table I) had hyperaminoaciduria, proteinuria, glucosuria, or increased urinary excretion of $3^{\prime}, 5^{\prime}$-cyclic AMP (cAMP).

A 43-yr-old man with long-standing, untreated nontropical sprue and osteomalacia served as hypophosphatemic control subject. The serum concentration of phosphorus was $1.8-2.0 \mathrm{mg} / 100 \mathrm{ml}$; calcium, $7.3 \mathrm{mg} / 100 \mathrm{ml}$; magnesium, $2.1 \mathrm{mg} / 100 \mathrm{ml}$; tatal protein, $7.0 \mathrm{~g} / 100 \mathrm{ml}$; albumin, 3.9 $\mathrm{g} / 100 \mathrm{ml}$; and alkaline phosphatase, $180-200 \mathrm{IU}$.

Two 27-yr-old normal men served as normophosphatemic control subjects.

Procedures. In all studies, a solution of calcium gluconate was administered intravenously from 6 p.m. to 12 midnight at a rate calculated to deliver $20-30 \mathrm{mg} / \mathrm{kg}$ of ionic calcium. The serum concentration of calcium was monitored hourly and the rate of infusion adjusted to maintain the concentration between 13 and $15 \mathrm{mg} / 100 \mathrm{ml}$. Urine flow and body weight were monitored throughout the period in which calcium was administered and for the next $8 \mathrm{~h}$; fluid losses were replaced with an intravenously administered hypotonic solution of sodium chloride $(0.45 \mathrm{~g} / 100 \mathrm{ml})$ to avoid an otherwise substantial reduction in extracellular fluid volume caused by calcium-induced natriuresis.

In each subject normocalcemia was documented at 8 a.m. on the morning after administration of calcium; intravenous administration of PTE was initiated approximately $2 \mathrm{~h}$ thereafter. PTE was administered at successively increasing constant rates of $0.1,0.4$, and $0.8 \mathrm{U} / \mathrm{kg}$ per $\mathrm{h}$, each rate lasting for $90 \mathrm{~min}$ (three clearance periods) (Table II). In separate studies of both hemizygotes, a solution of 0.15 $M$ sodium phosphate $\left(\mathrm{Na}_{2} \mathrm{HPO}_{4} / \mathrm{NaH}_{2} \mathrm{PO}_{4}\right.$, molar ratio $4: 1, \mathrm{pH} 7.4$ ) was intravenously administered as a "prime" before PTE was initiated and as a sustaining infusion during administration of PTE (Table II). The total infusate of sodium phosphate contained $0.15-0.30 \mathrm{mmol} / \mathrm{kg}$ of inorganic phosphate and $0.3-0.5 \mathrm{mmol} / \mathrm{kg}$ of sodium. PTE was not administered in single studies of normal subject W. V., hemizygote subject J. S., and hemizygote subject G. M., in whose study phosphate was administered as previously described.

Throughout all studies sequential measurements were made of the clearances of inulin and paraaminohippurate (PAH). Urine samples were obtained by voluntary voiding at 30-min intervals. Samples of arterialized blood were withdrawn from a superficial vein on the back of the hand that had been heated with an electric heating pad to $45^{\circ} \mathrm{C}$ or greater for more than $30 \mathrm{~min}$. Inorganic phosphate concentration was determined by autoanalyzer (15), calcium and magnesium determined by atomic absorption spectrophotometry, and chloride, sodium, potassium, and creatinine determined by autoanalyzer. Plasma and urine alpha-amino nitrogen, inulin, and $\mathrm{PAH}$; arterial $\mathrm{pH}, \mathrm{PcO}_{2}$; urinary ammonium, titratable acid, and $\mathrm{CO}_{2}$ content (16) ; and urinary cyclic adenine monophosphate (17) were determined by previously published methods. 
TABLE II

Physiological and Metabolic Effects of PTE and Sodium Phosphate Administered after Sustained Hypercalcemia in a Patient with FHR (GM)

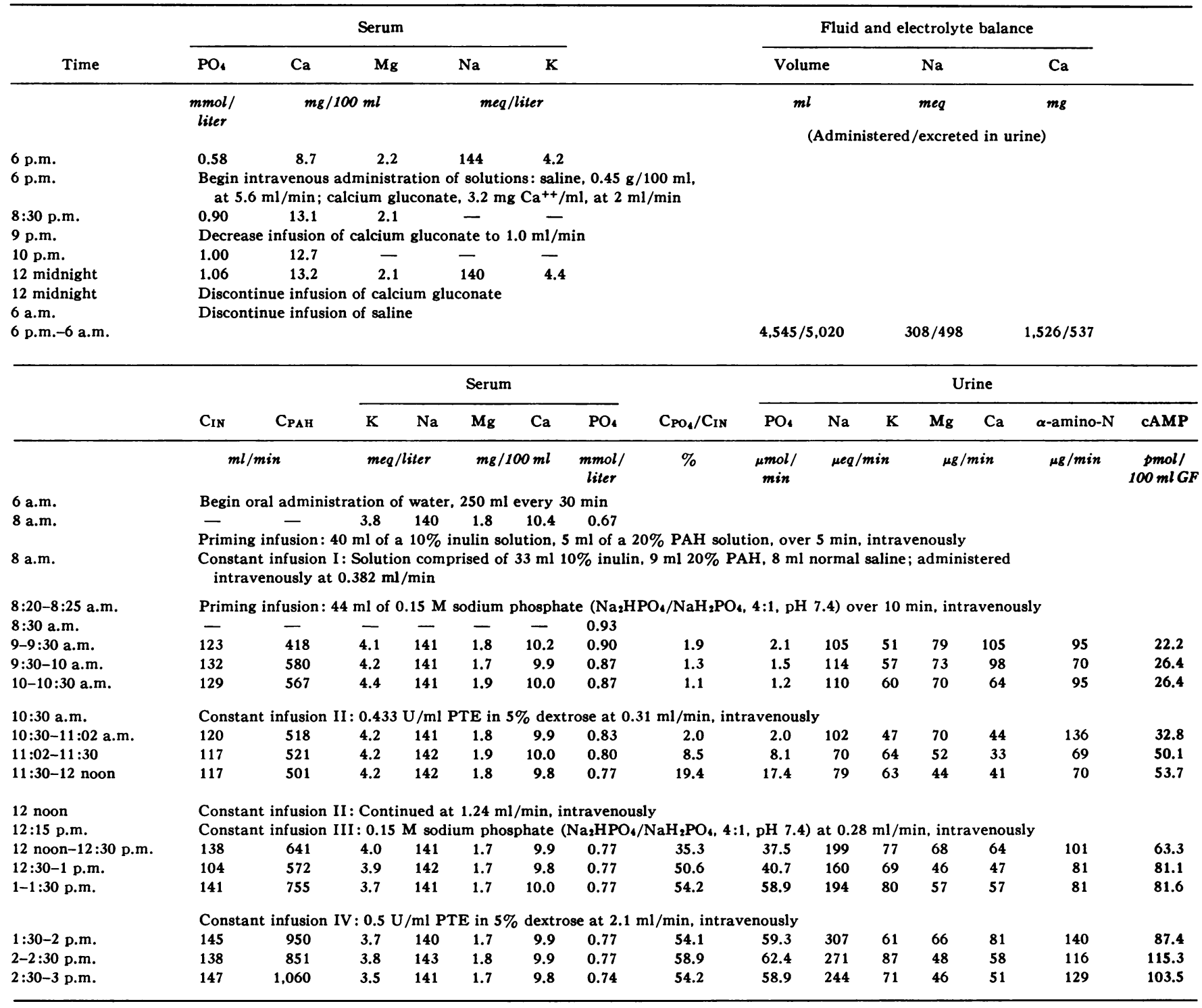

Abbreviations: $\mathrm{C}_{\mathrm{IN}}$, rate of glomerular filtration; $\mathrm{C}_{\mathrm{PAH}}$, rate of renal plasma flow; $\mathrm{C}_{\mathrm{PO}} / \mathrm{C}_{\mathrm{IN}}$, ratio of renal clearance of phosphate to renal clearance of inulin.

In the calculations of its renal clearance, inorganic phosphate was treated as if it were completely filterable (18, 19). Fractional excretion of filtered phosphate (FE POA) was calculated as renal clearance of phosphate/renal clearance of inulin $\times 100$. Statistical significance was determined by Student's unpaired $t$ test.

On plasma drawn at 6 p.m., immediately before calcium administration, and at 8 a.m. the next day, plasma immunoreactive parathyroid hormone (iPTH) concentration was determined by radioimmunoassay in the laboratory of Reitz and Weinstein, according to previously published methods (6). The human PTH used as a reference standard was derived from purification of parathyroid adenomas and has been previously characterized in relation to purified bovine PTH and the antibody (PG-I) $(20,21)$.

\section{RESULTS}

In both hemizygotes (studied in the posthypercalcemic state), FE PO4 remained negligible or quite reduced until PTE was administered, whereupon FE $\mathrm{PO}_{4}$ increased progressively and then plateaued at values at least twice those of control subjects studied in a similar way (Figs. 2,3 , and 4 and Table II). In both hemizygotes, this phosphaturic phenomenon occurred despite concom- 
itant hypophosphatemia of a severity (and duration) which in the hypophosphatemic control subject predictably precluded more than quantitatively trivial phosphaturia (Fig. 2). Despite phosphate loading, hypophosphatemia had recurred in both hemizygotes when the phosphaturic phenomenon occurred and remained throughout of a severity like that obtained without phos- phate loading (Fig. 3). Yet with phosphate loading, the maximal value of $\mathrm{FE} \mathrm{PO}_{4}$ attained in the hemizygotes during administration of PTE was $53 \pm 3.7 \%$ ( \pm 1 SD), compared to $23.9 \pm 2.3 \%$ in a normophosphatemic, normal control subject and $40 \pm 11.6 \%$ in the same hemizygotes without phosphate loading (Fig. 4). The maximal excretion rate of phosphate attained with PTE was
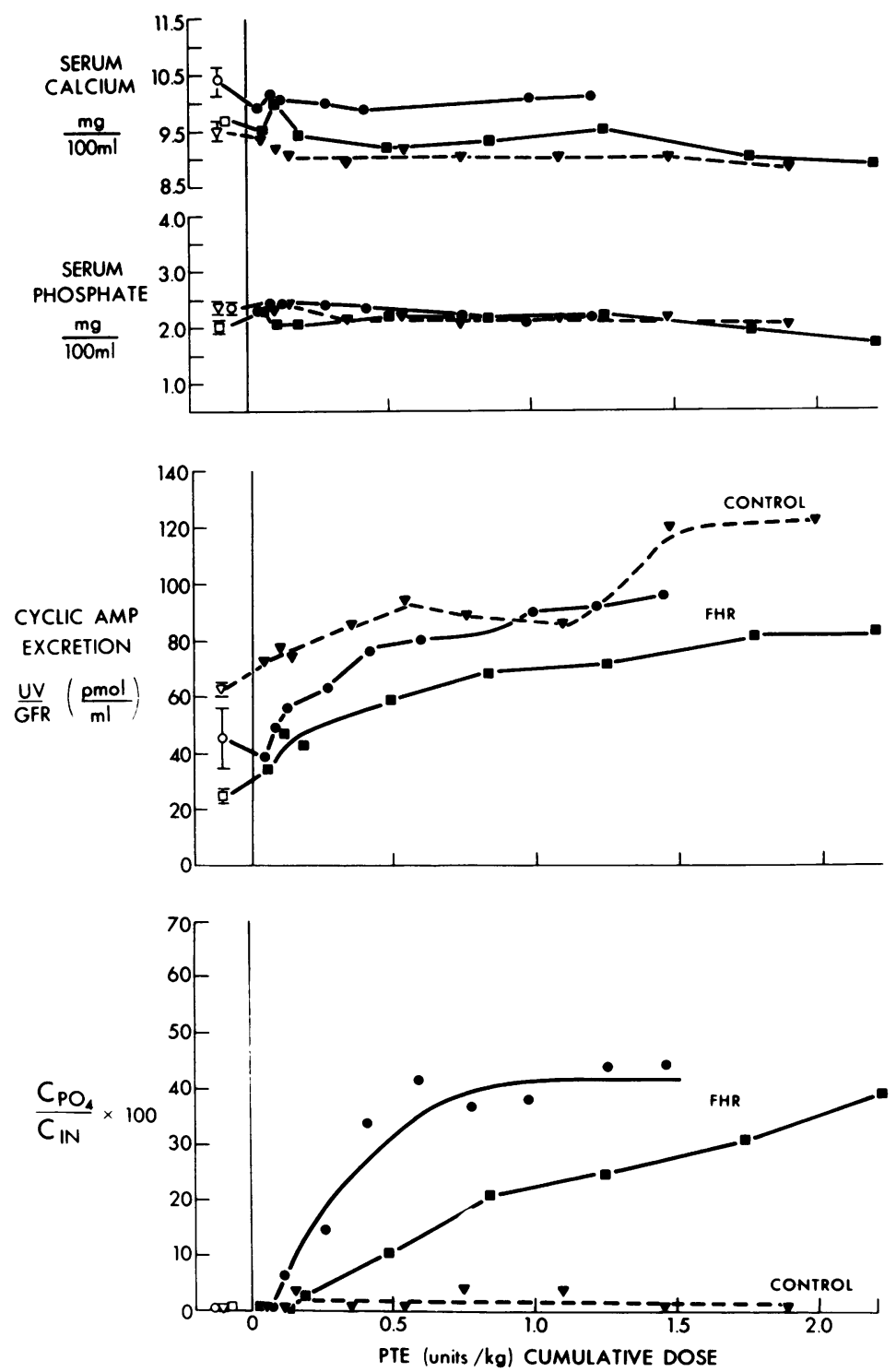

FIgURe 2 Physiologic response to continuous intravenous administration of PTE initiated almost immediately after termination of prolonged, experimentally induced hypercalcemia in two untreated adult hemizygotes with FHR (G. M. [०] and J. S. [ [ ], connected by unbroken lines) and one hypophosphatemic control subject ([ $\nabla]$, connected by broken lines). Depicted are the mean ( $\pm 1 \mathrm{SD}$ ) of values from three successive clearance periods obtained immediately before PTE was initiated (open symbols) and individual values thereafter (closed symbols). Cyclic AMP = 3',5'-cyclic AMP in $\mathrm{pmol} / \mathrm{ml}$ glomerular filtrate, a unit derived from urinary excretion rate (UV) divided by glomerular filtration rate (GFR) as measured by the renal clearance of inulin. $\mathrm{CPO}_{4} / \mathrm{CIN}_{\mathrm{IN}}=$ renal clearance of phosphate/renal clearance of inulin: fractional urinary excretion of filtered inorganic phosphate. 


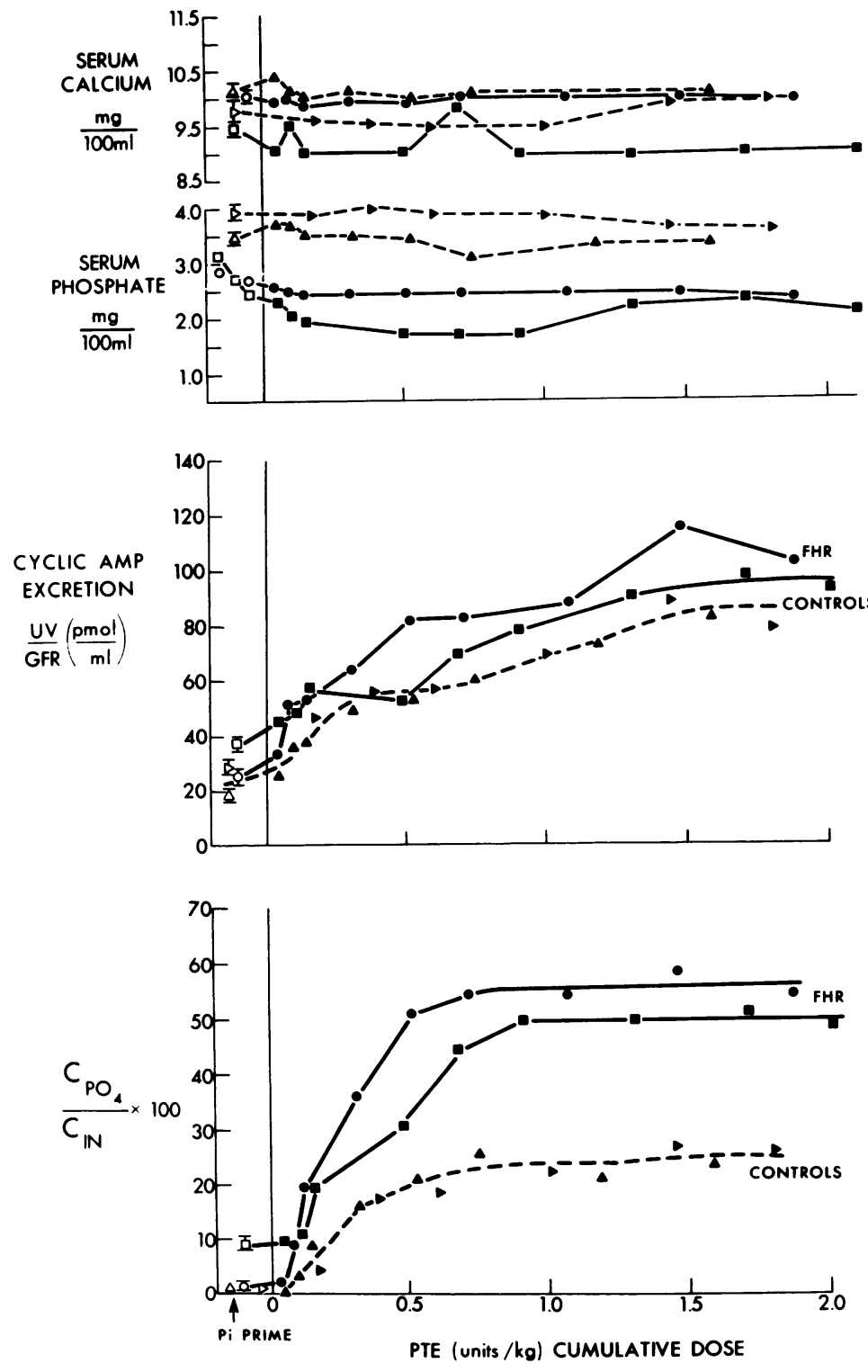

FIgURE 3 Physiologic response to continuous intravenous administration of PTE initiated almost immediately after termination of prolonged, experimentally induced hypercalcemia in two untreated adult hemizygotes with FHR (unbroken lines), who received an intravenously administered prime of neutral sodium phosphate (G. M. [ ] $6.6 \mathrm{mmol}$, J. S. [ ] $10.4 \mathrm{mmol}$ ) before clearance periods were begun, and in two normal control subjects ( $\boldsymbol{\Delta}$ and $\boldsymbol{\nabla}$, connected by broken lines.) Depicted are mean $( \pm 1 \mathrm{SD})$ of values from three successive clearance periods obtained immediately before PTE was initiated (open symbols) and individual values thereafter (closed symbols). Notations and units are as in Fig. 2.

also greater in phosphate-loaded hemizygotes $(38.7 \pm 4.3$ $\mu \mathrm{mol} / 100 \mathrm{ml}$ glomerular filtrate $[\mathrm{GF}]$ ) than in normal control subjects $(26.8 \pm 3.5 \mu \mathrm{mol} / 100 \mathrm{ml} \mathrm{GF} ; P<0.005)$ despite a significantly smaller filtered load of phosphate (Table III).

In nonphosphate-loaded hemizygotes, administration of PTE was attended by a decrease in the renal reab- sorption of phosphate from $69.6 \pm 4.8$ to $39.7 \pm 3.2 \mu \mathrm{mol} /$ $100 \mathrm{ml}$ GF $(P<0.001)$, a value significantly less than that obtained in the hypophosphatemic control subject $(65.8 \pm 1.7 \mu \mathrm{mol} / 100 \mathrm{GF})$ during administration of PTE (Table III). Studies were begun and concluded at similar serum phosphate concentrations and filtered loads of phosphate in the hemizygotes and hypophosphatemic con- 
TABLE III

Effect of Intravenously Administered PTE on Renal Reabsorption of Phosphate in Hemizygotes (FHR) and Control Subjects Studied in the Posthypercalcemic State

\begin{tabular}{|c|c|c|c|c|c|c|}
\hline \multirow[b]{3}{*}{ Subject } & \multicolumn{3}{|c|}{ Before PTE administration* } & \multicolumn{3}{|c|}{ During PTE administration $\ddagger$} \\
\hline & \multicolumn{6}{|c|}{ Phosphate } \\
\hline & Filtered & Excreted & Reabsorbed & Reabsorbed & Excreted & Filtered \\
\hline & \multicolumn{6}{|c|}{$\mu \mathrm{mol} / 100 \mathrm{ml} \mathrm{GF}$} \\
\hline $\begin{array}{l}\text { Hemizygotes (two) } \\
\text { (Nonphosphate-loaded) }\end{array}$ & $69.6 \pm 4.8$ & 0 & $69.6 \pm 4.8$ & $39.7 \pm 3.2$ & $25.8 \pm 5.0$ & $65.6 \pm 6.6$ \\
\hline $\begin{array}{l}\text { Control } \\
\text { (Hypophosphatemic) }\end{array}$ & $76.0 \pm 1.4$ & $\mathbf{0}$ & $76.0 \pm 1.4$ & $65.8 \pm 1.7$ & $0.89 \pm 1.3$ & $66.7 \pm 1.9$ \\
\hline$P$ value & NS & NS & NS & $<0.001$ & $<0.001$ & NS \\
\hline $\begin{array}{l}\text { Hemizygotes (two) } \\
\text { (Phosphate-loaded) }\end{array}$ & $88.6 \pm 7.6$ & $4.7 \pm 3.6$ & $83.9 \pm 7.0$ & $34.7 \pm 1.6$ & $38.7 \pm 4.3$ & $73.4 \pm 3.2$ \\
\hline $\begin{array}{l}\text { Controls (two) } \\
\text { (Normal) }\end{array}$ & $121.3 \pm 10.5$ & $\mathbf{0}$ & $121.3 \pm 10.5$ & $86.1 \pm 4.4$ & $26.8 \pm 3.5$ & $110.7 \pm 7.7$ \\
\hline$P$ value & $<0.001$ & $<0.02$ & $<0.001$ & $<0.001$ & $<0.005$ & $<0.001$ \\
\hline
\end{tabular}

* Mean value ( $\pm 1 \mathrm{SD}$ ) of three successive clearance periods immediately before administration of PTE.

$\ddagger$ Mean value $( \pm 1 \mathrm{SD})$ of three successive clearance periods during infusion of PTE at $0.8 \mathrm{U} / \mathrm{kg}$ per h, at which time the value of fractional excretion of filtered phosphate $\left(\mathrm{C}_{\mathrm{PO}{ }_{4}} \mathrm{C}_{\mathrm{IN}} \times 100\right)$ had reached a plateau (see Fig. 1).

trol subject (Table III). Similarly, serum calcium was within the normal range in each hemizygote and changed no more than $0.5 \mathrm{mg} / 100 \mathrm{ml}$ throughout the study.

In all subjects studied, the urinary excretion rate of cAMP was reduced until PTE was administered and in-

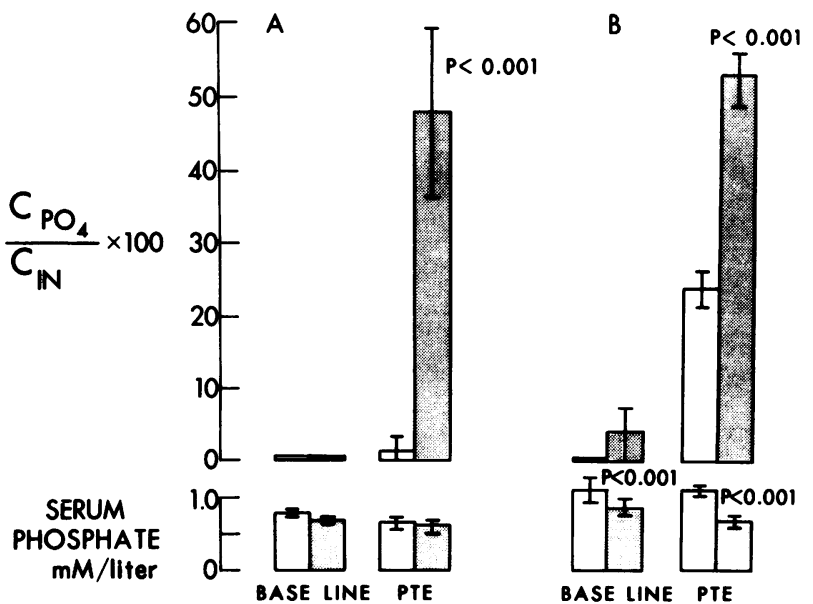

FIGURE 4 Comparison of fractional excretion of inorganic phosphate and serum inorganic phosphate in hemizygotes and control subjects during temporally comparable posthypercalcemic periods, before parathyroid extract was administered (Base line) and during the maximal excretion of phosphate that attended its administration (PTE). Bar graphs depict the mean ( \pm 1 SD) of values from three successive clearance periods. Open bars represent control subjects and solid bars hemizygotes. (A) Hemizygotes (two), and a hypophosphatemic control subject. (B) Phosphate-primed hemizygotes (two), and normal control subjects. creased progressively thereafter. At any cumulative dose of PTE, the rates of excretion of cAMP in the hemizygotes were similar to those of the other study subjects (Figs. 2 and 3 ).

When PTE was not administered during posthypercalcemic periods temporally comparable to those in which PTE was administered, fractional phosphate excretion and urinary excretion of cAMP remained reduced, in both the hemizygotes (irrespective of phosphate loading) and in the normal subjects (Figs. 5 and 6).

At the lower rates of PTE administration, 0.1-0.4 $\mathrm{U} / \mathrm{kg}$ per $\mathrm{h}$, and before significant changes in the GF rate or apparent renal plasma flow occurred, the values of fractional excretion of phosphate in the hemizygotes had increased significantly and were significantly greater than those in the control subjects (Figs. 2, 3, and 7). When PTE was administered at the rate of $0.8 \mathrm{U} / \mathrm{kg}$ per $\mathrm{h}$, both the GF rate and apparent renal plasma flow increased significantly in all studies (Table II). At any cumulative dose of PTE, the hemodynamic changes in the hemizygotes were indistinguishable from those of control subjects.

In those studies of hemizygotes in which sodium phosphate was not administered and in all studies of control subjects, fractional excretion of sodium and chloride did not change significantly during administration of PTE. In those studies of hemizygotes in which phosphate was administered, fractional excretion of sodium rose from $1.13 \pm 0.25 \%$ to $1.74 \pm 0.45 \% \quad(P<0.005)$ when PTE was administered; fractional excretion of chloride did 
not increase. In the pre-PTE control period, hemizygotes excreted significantly less calcium than the normal control subjects; the fractional excretion of $\mathrm{Ca}$ was $1.09 \pm 0.49$ and $1.55 \pm 0.37 \%$, respectively $(P<0.025)$. With administration of PTE, urinary excretion of calcium decreased somewhat in the normal control subjects but not in the hemizygotes.

Urinary excretion of bicarbonate increased significantly in both normal control subjects and hemizygotes when PTE was administered, but the increase in the hemizygotes was significantly less than in the normal control subjects in whom the maximal fractional excretion of filtered bicarbonate attained was only $1.6 \%$. With administration of PTE, urinary excretion of ammonium remained fixed in the hemizygotes and decreased somewhat in control subjects. In the hemizygotes, excretion of titratable acid increased from $12.9 \pm 3.2$ to $35.9 \pm$ $3.7 \mu \mathrm{mol} / 100 \mathrm{ml} \mathrm{GF}$ when PTE was administered with sodium phosphate, and to $27.1 \pm 3.4 \mu \mathrm{mol} / 100 \mathrm{ml}$ with PTE alone. In the control subjects, excretion of titratable acid did not change significantly when PTE was administered. In all studies, the arterial plasma bicarbonate concentration remained normal and did not change significantly when PTE was administered.

Glucosuria did not occur in any study. In all studies of

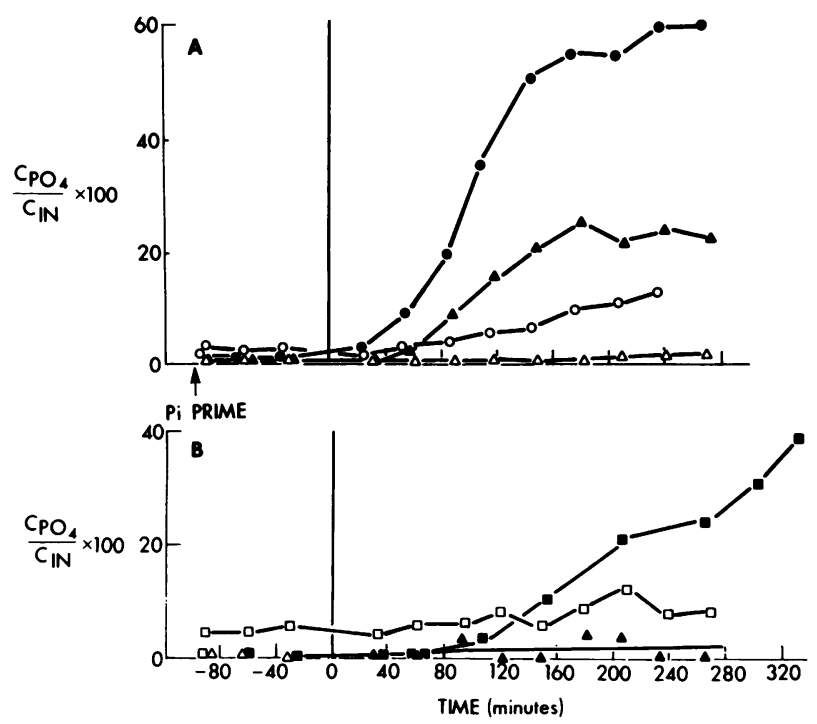

FIGURE 5 Comparison of fractional phosphate excretion over temporally comparable posthypercalcemic periods in which PTE was either administered (closed symbols) or withheld (open symbols) in both adult hemizygotes and control subjects. When administered, PTE was initiated at 0 time. (A) Individual clearance values for hemizygote G. M. (๑) who received $6.61 \mathrm{mmol}$ neutral sodium phosphate prime in both studies, and for a normophosphatemic control subject $(\boldsymbol{A})$. (B) Individual clearance values for hemizygote J. S. ( $\boldsymbol{\square})$, who received no phosphate prime and for a hypophosphatemic control subject $(\boldsymbol{\Delta})$.

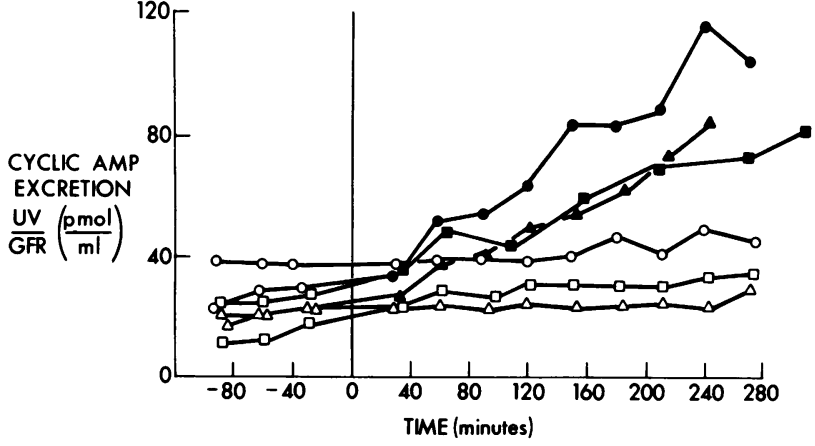

Figure 6 Urinary excretion of cAMP in hemizygotes and control subjects when PTE was administered (closed symbols) or withheld (open symbols) during temporally comparable posthypercalcemic states. Hemizygote G. M. (•) received a phosphate prime $(6.6 \mathrm{mmol})$ before clearance studies were begun in each study; hemizygate J. S. (a) received no phosphate prime. The control subject $(\boldsymbol{\Delta})$ was normophosphatemic. When administered, PTE was initiated at 0 time.

the hemizygotes, the urinary excretion rate of alphaamino nitrogen remained normal throughout and increased significantly only when PTE was administered at a rate of $0.8 \mathrm{U} / \mathrm{kg}$ per $\mathrm{h}$ and then to rates not significantly greater than those occurring in the normal subjects.

Before induction of hypercalcemia, the plasma concentration of iPTH in the hemizygotes, $424 \pm 125 \mathrm{pg} / \mathrm{ml}$ ( $\pm 1 \mathrm{SD}$ ), was not significantly different from that of

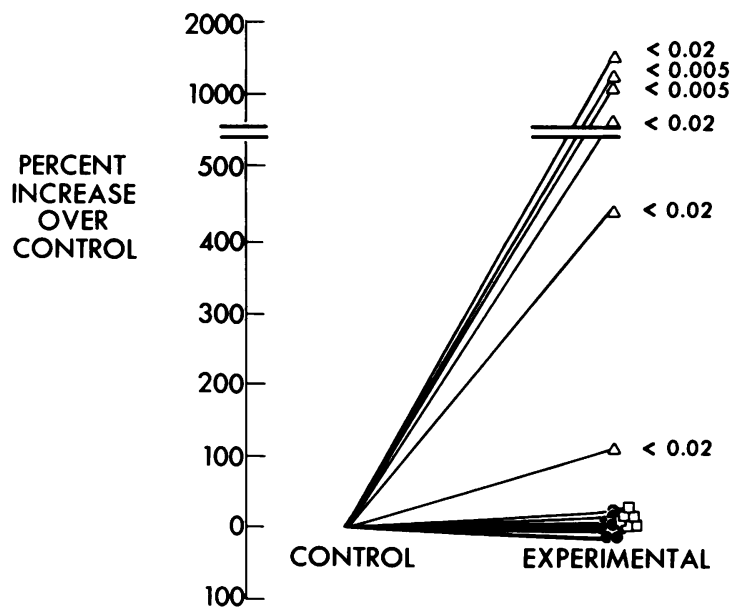

Figure 7 Percent increase in glomerular filtration rate (๑), apparent renal plasma flow (renal clearance of $\mathrm{PAH}$ ) $(\boldsymbol{D})$, and fractional phosphate excretion $(\boldsymbol{\Delta})$ over mean of control clearance periods (three) at the time when the values of $\mathrm{CPO}_{4} / \mathrm{CIN}_{\mathrm{N}}$ first became significantly greater than those of the control period in the hemizygotes and normal control subjects. This time ranged from 90-120 min after PTE was initiated. 
the normal control subjects, $484 \pm 83 \mathrm{pg} / \mathrm{ml}( \pm 1 \mathrm{SD})$, a value in the normal range established with the antibody used (6). After the occurrence of hypercalcemia, the mean decrease in plasma concentration of iPTH in the hemizygotes, $134 \pm 69 \mathrm{pg} / \mathrm{ml}$, was not significantly different from that in the normal control subjects, $187 \pm 95$ $\mathrm{pg} / \mathrm{ml}$.

\section{DISCUSSION}

The results of the present study indicate that in patients with FHR the phosphaturic response to circulating PTH is exaggerated. When PTE was intravenously administered to two adult hemizygotes with FHR in the posthypercalcemic state, FE PO, increased within minutes from a negligible value to values significantly greater than those of similarly studied control subjects, even though the filtered loads of phosphate in the hemizygotes were significantly lower than in the normal control subjects. The greater values of FE PO4 in the hemizygotes reflected rates of renal reabsorption of phosphate that were significantly less than those obtaining with identical cumulative doses of PTE in hypophosphatemic and normophosphatemic control subjects. The abrupt and striking increase in FE PO, that attended administration of PTE was clearly caused by an increase in the circulating level of renoactive PTH, and the increase would appear to have been from a reduced level. In both hemizygotes and control subjects, FE POA and urinary excretion of cAMP remained reduced long after termination of experimental hypercalcemia unless or until PTE was administered, whereupon the excretion of both cAMP and phosphate increased within minutes with no discernible difference in their times of onset. At any cumulative dose of PTE, urinary excretion of cAMP in the hemizygotes was indistinguishable from that of control subjects. An exaggerated phosphaturic response to PTE persisted in the patients with FHR throughout the $4 \frac{1}{2} \mathrm{~h}$ of PTE administration and could not be related to differences between patients and control subjects in extracellular volume $(22,23)$, serum calcium concentration during the study, percent of administered calcium retained, or renal hemodynamic changes. Moreover, only the phosphaturic response to PTE appeared to be exaggerated.

It might be argued that the patient with intestinal malabsorption, vitamin D deficiency, hypocalcemia, and secondary hyperparathyroidism was not an ideal hypophosphatemic control subject, since the phosphaturic response to PTE might be blunted by such consequences of malabsorption as contraction of extracellular fluid volume $(24,25)$, depletion of potassium $(22)$, and systemic acidosis (23). But none of these (nor hypomagnesemia) was present in this patient at the time of study, nor had they been present for at least 1 wk beforehand.
Although several observations suggest that vitamin D deficiency per se might act to dampen net renal tubule reabsorption of phosphate $(26,27)$, virtually complete net renal tubular reabsorption of phosphate has been observed in the vitamin D-deficient, hypophosphatemic, phosphate-depleted rat (28). Presumably, the "blunted" response to PTE in the hypophosphatemic, presumably phosphate-depleted control subject was a consequence of hypophosphatemia per se $(29,30)$.

The known and likely determinants of renal phosphate transport (with the obvious exceptions of the genetic defect and the hypophosphatemic state) were demonstrably equalized in the patients and normal control subjects of the present study. Only men $25 \mathrm{yr}$ of age or older were studied and none had received phosphate therapy, vitamin $\mathrm{D}$, or any of its analogues or derivatives for at least $1 \mathrm{yr}$ before study. Accordingly, interpretation of the physiological data is not complicated by whatever effects these agents or those metabolic events attending somatic growth might have on renal tubular transport of phosphate. When PTE was administered, the patients with FHR were not different from the normal control subjects with respect to posthypercalcemic status, plasma concentration of $\mathrm{PTH}$, renal tubular reabsorption of phosphate (approximately 100\%), serum concentration of calcium (normal), urinary excretion of cAMP, receipt of PTE on dose per unit weight basis, renal hemodynamics (as judged by measurements of the clearance of inulin and paraaminohippuric acid), and nonoccurrence of phosphaturia or increased cAMP excretion during temporally comparable posthypercalcemic periods in which PTE was not administered. The results of the studies thus provide the first convincing evidence that in the patients with FHR the phosphaturic response to $\mathrm{PTH}$ is exaggerated, and strongly suggest that the phenomenon reflects the genetic defect.

In two previously described boys with hypophosphatemic vitamin D-resistant rickets, the possibility that the phosphaturic response to administered PTE is exaggerated in patients with FHR can be entertained, but a definitive conclusion cannot be made because of uncertainties of diagnosis, experimental design, and metabolic state of the patients. In a 6-yr-old boy with hypophosphatemic vitamin D-resistant rickets studied by Fraser et al. (31) FHR could not be diagnosed because the boy's family history was "negative." In this patient, $200 \mathrm{U}$ of PTE were administered subcutaneously during a period of sustained intravenous administration of calcium begun $48 \mathrm{~h}$ earlier. In a single clearance period, that initiated by the administration of PTE, urinary excretion of phosphate increased from a negligible value to a value greater than the apparent values obtaining before administration of calcium. The possibility that the transient phosphaturic response was related to a marked 
increase in renal blood flow, which almost invariably occurs with large doses of PTE, could not be excluded since the only index of renal hemodynamics reported was the clearance of creatinine. Studies of control subjects were not reported. Given the uncertain growth status of the patient, it is problematic whether an appropriate control study could have been carried out. In a pubescent boy with hypophosphatemic vitamin D-resistant rickets studied by Magid et al. (13) at age 14 and $15 \mathrm{yr}$, after prolonged therapy with massive amounts of vitamin Da $(8,000,000$ IU day) had been discontinued for 6 wk and 1 day, respectively, PTE was administered intravenously as single injections of either 200 or $25 \mathrm{U}$, with and without prior induction of hypercalcemia. When PTE was administered, FE PO (clearance of phosphate/clearance of creatinine) increased transiently to values greater than those occurring in a normal subject of unspecified age, size, and growth status studied in a similar way. Measurements of renal blood flow were not reported. The patient may not have had classical FHR, since FE $\mathrm{PO}_{4}$ did not decrease after sustained hypercalcemia. Familial involvement could not be shown except for the patient's possibly affected mother in whom neither a posthypercalcemic reduction in $\mathrm{FE} P \mathrm{P}_{4}$ nor an exaggerated phosphaturic response to PTE could be demonstrated.

The present demonstration in the hemizygote that the value of $\mathrm{FE} \mathrm{PO}_{4}$ plateaued after administration of 1.0 $\mathrm{U} / \mathrm{kg}$ of PTE, despite further PTE administration (to 2.0 $\mathrm{U} / \mathrm{kg}$ ) and continued increase in urinary cAMP excretion, suggests the presence of a residual component of net phosphate reabsorption that is not responsive to PTE or conditioned by cAMP response, at least in the concentrations of PTE achieved in this study. This residual reabsorptive capacity was $34.7 \pm 1.6 \mu \mathrm{mol} / 100 \mathrm{ml} \mathrm{GF}$ with phosphate loading and $39.7 \pm 3.0 \mu \mathrm{mol} / 100 \mathrm{ml} \mathrm{GF}$ without phosphate loading, a nonsignificant difference. The data of Glorieux and Scriver suggest the presence of a similar residual component of net phosphate transport in hemizygotes with a capacity of approximately 50 $\mu \mathrm{mol} / 100 \mathrm{ml} \mathrm{GF}$ (7).

At any cumulative dose of PTE in hemizygotes, urinary excretion of cAMP was indistinguishable from that of control subjects irrespective of serum phosphate concentration, in accord with the findings of Glorieux and Scriver (7). In the hemizygote, the finding that the doseresponse relationship between administered PTE and cAMP excretion is indistinguishable from that of control subjects suggests that in patients with FHR the renal response to $\mathrm{PTE}$ is not abnormal with respect to membrane binding of PTE, adenyl cyclase activation (32), and cAMP production (33).

An exaggerated phosphaturic response to circulating PTH need not reflect an "abnormal" response of the renal tubule to $\mathrm{PTH}$ (or cAMP) at the cellular level of action of this hormone. Specifically, the exaggerated phosphaturic response to PTE need not reflect a state of hyperresponsiveness of those phosphate transport systems normally responsive to PTH. If in FHR the genetically transmitted abnormality acted to reduce reabsorption of phosphate in the proximal nephron by a PTHunresponsive mechanism, and if a normally large rate capacity for phosphate reabsorption in the distal nephron were inhibited by normal levels of PTH (34-41), the magnitude of phosphaturia would be greater in patients with FHR than in normal subjects at similar filtered loads of phosphate and circulating levels of PTH, even though responsiveness of the renal tubule to $\mathrm{PTH}$ was normal at the cellular level. The difference in rate of phosphate excretion would reflect the difference in rate of delivery of phosphate out of the proximal nephron. If, in the absence of PTH, the rate capacity for phosphate reabsorption in the distal nephron were sufficiently great, net renal reabsorption of filtered phosphate in FHR might be complete despite the persistence of a substantially reduced net reabsorption rate of phosphate in the proximal nephron. In this circumstance, PTH could be said to "unmask" the abnormality of the PTH-unresponsive phosphate transport mechanism of the proximal nephron. It is apparent that the unmasking of an abnormality of the PTH-unresponsive phosphate transport mechanism in the proximal nephron might also be contributed to (or even accounted for) by the effect of PTE to further decrease reabsorption of phosphate in the proximal nephron.

The results of the present study are also consistent with the possibility that in patients with FHR, a PTHresponsive phosphate transport mechanism in the proximal and(or) distal nephron is genetically altered such that it is hyperresponsive to the phosphaturic effect of PTH. Such hyperresponsiveness might stem from a genetically determined defect in one of the determinants of the PTH-responsive phosphate transport system or in the transport system per se. In patients with FHR, the increase in intracellular concentration of cAMP induced in the renal tubule by subphysiological amounts of PTH might be greater than that induced in normal subjects. The finding of a similar, PTH-induced increase in urinary excretion of cAMP in the patients with FHR and control subjects provides no support for this possibility but does not exclude it. In FHR, hyperresponsiveness to the phosphaturic response to $\mathrm{PTH}$ could reflect a genetic defect in a component of the phosphate transport system that normally acts to dampen the phosphaturic response to $\mathrm{PTH}$-induced increase in intracellular concentration of cAMP.

In patients with FHR, a genetically determined defect in the metabolism of vitamin $D$ could underlie the 
exaggerated phosphaturic response to PTH. $25(\mathrm{OH}) \mathrm{D}_{3}$, the principal initial metabolite of vitamin $D_{3}$ (42), can act directly on the renal tubule to increase its net phosphate reabsorption $(27,43,44)$ and, in parathyroidectomized rats, to blunt the phosphaturic response to administered PTH (43). Although it is not clear that $25(\mathrm{OH}) \mathrm{D}_{3}$ or its metabolite $1,25(\mathrm{OH})_{2} \mathrm{D}_{3}$ (which is made exclusively in the renal cortex) (45-47) acts directly on the PTH-responsive phosphate transport system, $25(\mathrm{OH}) \mathrm{D}_{3}$ acts to enhance renal reabsorption of phosphate in the rat only in the presence of PTH (43, 44). This suggests that PTH may act to convert 25$(\mathrm{OH}) \mathrm{D}_{\mathbf{s}}$ to a metabolite normally required for enhanced renal transport of phosphate. PTH is known to enhance conversion of $25(\mathrm{OH}) \mathrm{D}_{3}$ to $1,25(\mathrm{OH})_{2} \mathrm{D}_{3}(48,49)$ and possibly to $24,25(\mathrm{OH})_{2} \mathrm{D}_{3}$ as well in some circumstances (50). The PTH-responsive phosphate transport system might then normally be modulated by $25(\mathrm{OH}) \mathrm{D}_{3}$ or one of its metabolites such as to dampen the phosphaturic effect of PTH. If so, hyperresponsiveness to the phosphaturic effect of PTH in patients with FHR might reflect a genetic defect that acts to prevent or dampen the conversion of $25(\mathrm{OH}) \mathrm{D}_{3}$ to a metabolite that normally acts on the PTH-responsive transport system to blunt the phosphaturic effect of PTH.

\section{ACKNOWLEDGMENTS}

We gratefully acknowledge the expert technical assistance of Kathleen Nigon, Jeannette Benoit, Joan Schweiger, Ann Ince, and Zora Cecich. We are also pleased to acknowledge the continuing help of Jane Wylie and the nursing staff of the General Clinical Research Center at the Moffitt Hospital.

These studies were supported by grants from the Division of Research Facilities and Resources, National Institutes of Health (RR 00079) and from the U. S. Public Health Service, National Institute of Arthritis, Metabolism, and Digestive Diseases (AM 16764).

\section{REFERENCES}

1. Winters, R. W., J. B. Graham, T. F. Williams, V. W. McFalls, and C. H. Burnett. 1958. A genetic study of familial hypophosphatemia and vitamin $D$ resistant rickets with a review of the literature. Medicine (Baltimore). 37 : 97-142.

2. Williams, T. F., R. W. Winters, and C. H. Burnett. 1972. Familial (hereditary) vitamin D-resistant rickets with hypophosphatemia. In The Metabolic Basis of Inherited Disease. J. B. Stanbury, J. B. Wyngaarden, and D. S. Fredrickson, editors. McGraw-Hill, Inc., New York. 3rd edition. 1465-1485.

3. Arnaud, C., F. Glorieux, and C. R. Scriver. 1971. Serum parathyroid hormone in $\mathrm{x}$-linked hypophosphatemia. Science (Wash. D. C.). 173: 845-847.

4. Roof, B. S., C. F. Piel, and G. S. Gordan. 1972. Nature of defect responsible for familial vitamin D-resistant rickets (VDRR) based on radioimmunoassay for parathyroid hormone (PTH). Trans. Assoc. Am. Physicians Phila. 85: 172-180.

5. Lewy, J. E., E. C. Cabana, H. A. Repetto, J. M. Canterbury, and E. Reiss. 1972. Serum parathyroid hormone in hypophosphatemic vitamin D-resistant rickets. J. Pediatr. 81 : 294-300.

6. Reitz, R. E., and R. L. Weinstein. 1973. Parathyroid hormone secretion in familial vitamin-D-resistant rickets. N. Engl. J. Med. 289: 941-945.

7. Glorieux, F., and C. R. Scriver. 1972. Loss of a parathyroid hormone-sensitive component of phosphate transport in $\mathrm{x}$-linked hypophosphatemia. Science (Wash. D. C.). 175 : $997-1000$.

8. Lestradet, H., P. Royer, and D. Jacob. 1958. Resultats fournes par l'épreuve de perfusion calcique dans le rachitisme vitamine-résistant hypophosphatémique idiopathique. Rev. Fr. Etud. Clin. Biol. 3: 884-886.

9. Lamy, M., P. Royer, J. Frézal, and H. Lestradet. 1958. Le rachitisme vitamino-résistant familial hypophosphatémique primitif. Arch. Fr. Pediatr. 15: 1-24.

10. Field, M. H., and E. Reiss. 1960. Vitamin D-resistant rickets: The effect of calcium infusion of phosphate reabsorption. J. Clin. Invest. 39: 1807-1812.

11. Falls, W. F., Jr., N. W. Carter, F. C. Rector, Jr., and D. W. Seldin. 1968. Familial vitamin D-resistant rickets. Study of six cases with evaluation of the pathogenetic role of secondary hyperparathyroidism. Ann. Int. Met. 68: $533-560$.

12. Harrison, H. E. 1959. Discussion after paper by Fraser et al. (Ref. 31) Helv. Paediatr. Acta. 14: 504-505.

13. Magid, G. J., J. R. Maloney, J. H. Sirota, and E. A. Schwab, Jr. 1966. Familial hypophosphatemia. Studies on its pathogenesis in an affected mother and son. Ann. Intern. Med. 64 : 1009-1027.

14. Blackard, W. G., R. R. Robinson, and J. E. White. 1962. Familial hypophosphatemia. Report of a case, with observations regarding pathogenesis. N. Engl. J. Med. 266 : 899-905.

15. Fiske, C. H., and Y. Subbarow. 1925. The calorimetric determination of phosphorus. J. Biol. Chem. 66: 375-400.

16. Morris, R. C., Jr. 1968. An experimental renal acidification defect in patients with hereditary fructose intolerance. I. Its resemblance to renal tubular acidosis. $J$. Clin. Invest. 47 : 1389-1398.

17. Johnson, R. A., J. G. Hardman, A. E. Broadus, and E. W. Sutherland. 1970. Analysis of adenosine $3^{\prime}, 5^{\prime}-$ monophosphate with luciferase luminescence. Anal. Biochem. 35: 91-97.

18. Walser, M. 1960. Protein-binding of inorganic phosphate in plasma of normal subjects and patients with renal disease. J. Clin. Invest. 39 : 501-506.

19. Walser, M. 1961. Ion association. VI. Interactions between calcium, magnesium, inorganic phosphate, citrate and protein in normal human plasma. J. Clin. Invest. 40: 723-730.

20. O'Riordan, J. L. H., G. D. Aurbach, and J. T. Potts, Jr. 1969. Immunological reactivity of purified human parathyroid hormone. Proc. Natl. Acad. Sci. U. S. A. 63: 692-698.

21. Segre, G. V., J. F. Habener, D. Powell, G. W. Tregear, and J. T. Potts, Jr. 1972. Parathyroid hormone in human plasma. Immunochemical characterization and biological implications. J. Clin. Invest. 51: 3163-3172.

22. Beck, N., H. Singh, and B. B. Davis. 1973. Impaired phosphaturic response to parathyroid hormone (PTH) in $\mathrm{K}^{+}$depleted $\left(\downarrow \mathrm{K}^{+}\right)$rats: Its pathogenic site at cyclic AMP (cAMP). Clin. Res. 21: 676. (Abstr.)

23. Beck, N., H. P. Kim, and K. S. Kim. 1975. Effect of metabolic acidosis on renal action of parathyroid hormone. Am. J. Physiol. 228: 1483-1488. 
24. Massry, S. G., J. W. Coburn, and C. R. Kleeman. 1969. The influence of extracellular volume expansion on renal phosphate reabsorption in the dog. J. Clin. Invest. 48: 1237-1245.

25. Suki, W. N., M. Martinez-Maldonado, D. Rouse, and A. Terry. 1969. Effect of expansion of extracellular fluid volume on renal phosphate handling. J. Clin. Invest. 48: $1888-1894$.

26. Puschett, J. B., J. Moranz, and W. S. Kurnick. 1972. Evidence for a direct action of cholecalciferol and 25hydroxycholecalciferol on renal transport of phosphate, sodium, and calcium. J. Clin. Invest. 51: 373-385.

27. Costanzo, L. S., P. R. Sheehe, and I. M. Weiner. 1974. Renal actions of vitamin $\mathrm{D}$ in $\mathrm{D}$-deficient rats. $\mathrm{Am}$. J. Physiol. 226: 1490-1495.

28. Steele, T. H., J. E. Engle, Y. Tanaka, R. S. Lorenc, K. L. Dudgeon, and H. F. DeLuca. 1975. Phosphatemic action of 1,25-dihydroxyvitamin $\mathrm{D}_{3}$. Am. J. Physiol. 229 : 489-495.

29. Shikita, M., S. Tsurufuji, and Y. Ito. 1962. Adaptation in renal phosphorus excretion under the influence of parathyroids; a study in unilaterally catheterized rats. Endocrinol. Jpn. 9 : 171-180.

30. Thompson, D. D., H. H. Hiatt. 1957. Effects of phosphate loading and depletion on renal excretion and reabsorption of inorganic phosphate. J. Clin. Invest. 36: 566-572.

31. Fraser, D., J. M. Leeming, and E. A. Cerwenka. 1959. Úber die Handhabung von Phosphat durch die Nieren bei hypophosphatämischer vitamin-D-resistenter Rachitis der einfachen Art und bei Cystinspeicherkrankheit. Reaktion auf verlängerte Calciuminfusion. Helv. Paediatr. Acta. 14 : 497-505.

32. Canterbury, J. M., G. S. Levey, and E. Reiss. 1973. Activation of renal cortical adenylate cyclase by circulating immunoreactive parathyroid hormone fragments. J. Clin. Invest. 52 : 524-527.

33. Kaminsky, N. I., A. E. Broadus, J. G. Hardman, D. J. Jones, Jr., J. H. Ball, E. W. Sutherland, and G. W. Liddle. 1970. Effects of parathyroid hormone on plasma and urinary adenosine $3^{\prime}, 5^{\prime}$-monophosphate in man. $J$. Clin. Invest. 49 : 2387-2395.

34. Amiel, C., H. Kuntziger, and G. Richet. 1970. Micropuncture study of handling of phosphate by proximal and distal nephron in normal and parathyroidectomized rat. Evidence for distal absorption. Pflugers Arch. Eur. J. Physiol. 317 : 93-109.

35. Herbert, C. S., D. Rouse, G. Eknoyan, M. MartinezMaldonado, and W. M. Suki. 1972. Decreased phosphate reabsorption by volume expansion in the dog. Kidney Int. 2 : 247-252.

36. Beck, L. H., and M. Goldberg. 1973. Effect of acetazolamide and parathyroidectomy on renal transport of sodium, calcium, and phosphate. Am. J. Physiol. 224: $1136-1142$.

37. Wen, S-F. 1974. Micropuncture studies of phosphate transport in the proximal tubule of the dog. The relationship to sodium reabsorption. J. Clin. Invest. 53: 143-153.

38. Beck, L. H., and M. Goldberg. 1974. Mechanism of the blunted phosphaturia in saline-loaded thyroparathyroidectomized dogs. Kidney Int. 6: 18-23.

39. Chiu, P. J. S., Z. S. Agus, and M. Goldberg. 1974. Effect of thyroparathyroidectomy (TPTX) on renal phosphate transport in the rat. Clin. Res. 22: 520A. (Abstr.)

40. Goldfarb, S., L. H. Beck, Z. S. Agus, and M. Goldberg. 1974. Dissociation between the sites of action of PTH and saline on renal phosphate $(\mathrm{P})$ reabsorption. Clin. Res. 22 : 528A. (Abstr.)

41. Knox, F. G., and C. Lechene. 1975. Distal site of action of parathyroid hormone on phosphate reabsorption. $\mathrm{Am}$. J. Physiol. 229 : 1556-1560.

42. Blunt, J. W., H. F. DeLuca, and H. K. Schnoes. 1968 25-hydroxycholecalciferol. A biologically active metabolite of vitamin $\mathrm{D}_{3}$. Biochemistry. 7: 3317-3322.

43. Popovtzer, M. M., J. B. Robinette, H. F. DeLuca, and M. F. Holick. 1974. The acute effect of 25-hydroxycholecalciferol on the renal handling of phosphorus. Evidence for a parathyroid hormone-dependent mechanism. J. Clin. Invest. 53: 913-926.

44. Puschett, J. B., W. S. Beck, Jr., and A. Jelonek. 1975. Parathyroid hormone and 25-hydroxyvitamin $D_{3}$ : synergistic and antagonistic effects on renal phosphate transport. Science (Wash. D. C.). 190: 473-475.

45. Fraser, D. R., and E. Kodicek. 1970. Unique biosynthesis by kidney of a biologically active vitamin $\mathrm{D}$ metabolite. Nature (Lond.). 228: 764-766.

46. Gray, R., I. Boyle, and H. F. DeLuca. 1971. Vitamin D metabolism: the role of kidney tissue. Science (Wash. D. C.). 172 : $1232-1234$.

47. Gray, R. W., J. L. Omdahl, J. G. Ghazarian, and H. F. DeLuca. 1972. 25-hydroxycholecalciferol-1-hydroxylase. Subcellular location and properties. J. Biol. Chem. 247 : 7528-7532.

48. Garabedian, M., M. F. Holick, H. F. DeLuca, and I. T. Boyle. 1972. Control of 25-hydroxycholecalciferol metabolism by parathyroid gland. Proc. Natl. Acad. Sci. U.S. A. 69: 1673-1676.

49. Rasmussen, H., H. M. Wong, D. Bikle, and D. B. P Goodman. 1972. Hormonal control of the renal conversion of 25-hydroxycholecalciferol to 1,25-dihydroxycholecalciferol. J. Clin. Invest. 51: 2502-2504.

50. Mawer, E. B., J. Backhouse, L. F. Hill, G. A. Lumb, P. De Silva, C. M. Taylor, and S. W. Stanbury. 1975. Vitamin D metabolism and parathyroid function in man. Clin. Sci. Mol. Med. 48 : 349-365. 